\title{
Improvement of the Governance Mechanism against Wildlife Crime Linked to the Internet in China
}

\author{
Xiumei Wang, Zhijuan Chen \\ College for Criminal Law Science, Beijing Normal University, Beijing, China \\ Email: tengfei883@163.com
}

How to cite this paper: Wang, X. M., \& Chen, Z. J. (2019). Improvement of the Governance Mechanism against Wildlife Crime Linked to the Internet in China. Beijing Law Review, 10, 1225-1238. https://doi.org/10.4236/blr.2019.105066

Received: October 29, 2019

Accepted: December 2, 2019

Published: December 5, 2019

Copyright $\odot 2019$ by author(s) and Scientific Research Publishing Inc. This work is licensed under the Creative Commons Attribution International License (CC BY 4.0).

http://creativecommons.org/licenses/by/4.0/

\begin{abstract}
The modern society has stepped into an information- and network-based new age that is globalized. Rapidly rising Internet technology and e-commerce play a tremendously positive role in promoting the social advance, technological innovation and economic development, but in the meantime, they exert negative impact in certain areas and various crime activities executed with use of the Internet technology surge consequently. Historically speaking, wildlife crime used to take place in the traditional market, but as Internet is popularized amid its fast development, more and more wildlife criminals are coming into the enormous virtual market via Internet, making wildlife crime one that is linked to the Internet. In recent years, TRAFFIC ${ }^{1}$ China has been conducting long-term monitoring over online trading platforms and the monitoring result shows that illicit wildlife trade in China has been transferred from physical market to online trading platforms and has been extended to social media platforms (Huanqiu Net, 2019). Online selling and online payment have become the major mode of wildlife crime linked to the Internet. However, compared with the continuously intensified combat against wildlife crime in the visible market in China, the fight against wildlife crime linked to the Internet still faces many new challenges. The paper introduces the basic concept, main characteristics and global trend of wildlife crime linked to the Internet, clarifies the international consensus on the combat against the crime, analyzes the experience and challenges of China in governing the crime and proposes the governing direction and advices on countermeasures for the country.
\end{abstract}

${ }^{1}$ TRAFFIC is a leading NGO working globally on trade in wild animals and plants in the context of both biodiversity conservation and sustainable development. More details refer to https://www.traffic.org/. 


\section{Keywords}

Wildlife Crime Linked to the Internet, Main Characteristics, Legal

Regulation, Comprehensive Governance, International Cooperation

\section{Introduction}

\subsection{Basic Concept of Wildlife Crime Linked to the Internet}

The concept of wildlife crime linked to the Internet is not legislatively specified yet in the laws and regulations in China and no consensus on the concept has been reached in the academic circle and judicial practice. According to the definition of "cybercrime" given by International Criminal Police Organization (INTERPOL), cyber-enabled crimes refer to a series of traditional crimes that go through "new changes" along with the rise of Internet (including financial crime and terrorism crime), and wildlife crime linked to the Internet should be taken as a type of cyber-enabled crime (TRAFFIC REPORT, 2019). According to the advices on legal terms for wildlife crime in CITES $^{2}$ CoP18's executive committee report Combating Wild Animal Cyber Crime, cybercrime is a two-dimensional concept, including both cyber-dependent and cyber-enabled crime (CITES REPORT, 2019). Cyber-dependent crime can be interpreted as the crime that damages the computer network or its data, while cyber-enabled crime can be interpreted as the crime of using modern information and communications technology, social media, e-commerce platforms, dark net or similar instruments to promote illegal drug and weapon trade, human trafficking and illegal wildlife trade. Therefore, wildlife cybercrime can be taken as a type of cyber-enabled crime, but use of the term "wildlife crime linked to the Internet" would be more appropriate. For this reason, as different from traditional illegal capturing of wildlife and related visible forms of trade, wildlife cybercrime in this paper refers to wildlife crime linked to the Internet.

\subsection{Main Characteristics of Wildlife Crime Linked to the Internet}

Wildlife crime linked to the Internet refers to the criminal acts of using Internet as a new tool or means of crime to illegally purchase, transport, process, sell and smuggle wildlife and their products in violation of national or international laws and regulations. Its main characteristics are introduced as follows. Firstly, it is a traditional crime in nature, a traditional crime that is executed with the use of computer or network technology as a tool or means of crime. This is different from the traditional illegal trade. Secondly, the means of crime is highly invisibility. Convenience and relative anonymity of the Internet technology offer greater possibilities to criminals for hiding their identity and avoiding legal accountability. Trade on the dark net that is facilitated by Bitcoin and other cryp${ }^{2}$ CITES: Convention on International Trade in Endangered Species of Wild Fauna and Flora. 
to-currencies might especially be preferred by more and more traders and consumers in the future because of its strict anonymity and high elusiveness. Crime is more flexible and diverse. Thirdly, the criminal behavior is complex and the subject of crime is diverse. Wildlife crime involves smuggling, illegal trade on-line, network transactions, transportation and other forms of behavior. The subject of crime involves poachers, processors, traders, transporters, sellers, consumers, network support platforms and other types. In recent years, a number of evidences show that the trend of organized criminal groups to participate in wildlife network crime is more and more prominent. Fourthly, it shows the trend of globalized development. Because of the emergence of the Internet, crime is not limited to one country or region. The international community has reached consensus on the transnational attribute of wildlife crime, which has already been verified by multiple studies. The broad international market that is fully opened $24 / 7$ as provided by Internet drives the globalized legitimate trade to prosper, but also offers more opportunities and platforms to wildlife crime linked to the Internet. Fifth, the crime rate rises year by year. The growth trend is clear and higher than when the Internet was not involved. As the network technology is increasingly popularized, the space of cybercrime is constantly expanded and the cybercrime rate is rising year by year. According to the 44th China Statistical Report on Internet Development released by China Internet Network Information Center (CNNIC), as of June 2019, there were 854 million netizens in China; popularity rate of Internet reached up to $61.2 \%$; there were 639 million online shoppers, accounting for $74.8 \%$ of the total netizens (CNNIC REPORT, 2019). The 2017 Regulatory Report on the Courier Market showed that in 2017, trade volume of Chinese courier enterprises reached 40.07 billion parcels, accounting for $40 \%$ of the world's total and ranking first globally for the fourth consecutive year (SPB REPORT, 2019). The rapid development of e-commerce and courier service in China creates ideal infrastructure for wildlife crime linked to the Internet. While e-commerce and the express delivery industry bring convenience to people, they also provide opportunities for criminals. Currently, online platforms and social media (WeChat, Baidu Tieba, Taobao, Facebook and Instagram etc.) have become popular platforms for illegal trade of endangered wildlife and their products.

\section{Development Trend of Wildlife Crime Linked to the Internet}

The combat against wildlife crime linked to the Internet is a challenge faced by the whole world and also a top priority on the agenda of the international community. Due to the characteristics of wildlife crime linked to the Internet, one country or region alone has not been able to completely solve the problem. In 2019, the World Animal Protection pointed out in the world's first Report on Global Wildlife Exotic Pet Trade that currently, over 500 species of birds and 500 species of reptiles were being traded globally. Global trade value of wildlife 
each year reached up to USD30 billion to USD42 billion, among which illegal trade value was approximated at USD20 billion (Xinhua Net, 2019). In 2019, International Air Transport Association (IATA) also pointed out that annual illegal trade value of wild animals and wild animal products (excluding wood and fishery) globally was around USD19 billion. The amount is huge and shocking. The illegal trade became one of the world's most serious crime activities right after drug, counterfeit currency and human trafficking and was regarded as an organized crime with high income yet low risk. Following a trend, it is likely that more criminals will take risks and get involved in wildlife crime linked to the Internet (IATA, 2019).

In 2018, International Fund For Animal Welfare (IFAW) that has been dedicated to study on online trade of wildlife issued its latest report, which revealed that through the six-week online trade monitoring in France, Germany, Russia and Britain, researchers found 11,772 specimens of endangered and threatened wildlife that were worth USD3,942,329 in 5381 pieces of ads on 110 online platforms. This means that, with the power of the Internet, criminals can more easily publish information about their illegal trade (IFAW, 2018). Let's take a look at China, The 2014 report of IFAW showed that China had the largest volume of sales in the global wildlife online trade monitoring, with 18,590 commodities being found in 2106 pieces of ads on 21 online platforms, worth RMB16,915,667 (IFAW, 2014).

The series of criminal data shows that wildlife crime linked to the Internet is a severe global problem, which requires not only the great attention of government of all countries and the international community as well as the participation and support of related enterprises and various forces in the society, but also deepened international cooperation to jointly crack down on and contain wildlife crime linked to the Internet.

\section{International Consensus on the Combat against Wildlife Crime Linked to the Internet}

As people are increasingly more aware of the harmfulness and universality of wildlife crime linked to the Internet, the international community reaches extensive consensus on necessity of the crackdown on the wildlife crime linked to the Internet.

\subsection{At the Level of International Law}

At the level of international law, international conventions such as the Budapest Convention, the Convention on International Trade in Endangered Species of Wild Fauna and Flora (CITES) ${ }^{3}$, the Convention on Biological Diversity and the U.N. Convention against Transnational Organized Crime directly or indirectly provide administrative specifications and effective approaches for handling the ${ }^{3}$ See Convention on International Trade in Endangered Species of Wild Fauna and Flora, https://www.cites.org/sites/default/files/eng/disc/CITES-Convention-EN.pdf. 
illicit wildlife trade. Currently, the only international legal instrument that targets at cybercrimes is the Budapest Convention. Since its taking effect in 2004, it has been approved by 57 countries so far, including the majority of the European Council member states and some non-member states such as Japan, United States, Canada and Australia (Xu, 2017). Though the Budapest Convention does not particularly target wildlife cybercrimes, it offers some legal support for investigating the issue. For instance, it authorizes enforcement authorities for searching computer network and intercepting, collecting and keeping the network data and offers even greater right of detention. Besides, another convention related to wildlife trade is the CITES, which is the only convention focused on international wildlife trade and also the foremost prerequisite and legal foundation for the international community to combat the wildlife crime linked to the Internet. At present, CITES has 183 parties to ensure that international trade in wild fauna and flora does not threaten the survival of wild fauna and flora to the maximum extent. Of course, we need more and more perfect and wider applicability of international law to support the judicial departments of various countries and regions to enforce the law and intensify the fight against crimes.

\subsection{At the Level of International Organizations}

At the level of international organizations, the main international organizations making major contributions to fighting against transnational wildlife crime. In 2010, the CITES secretariat, INTERPOL, United Nations Office on Drugs and Crime (UNODC), World Bank and World Customs Organization set up the International Consortium on Combating Wildlife Crime (ICCWC) to enhance international cooperation against wildlife crime (Qin, 2016). ICCWC member states released a series of reports and toolkits for fighting the wildlife crime. UNODC especially played an important role in this aspect. On the one hand, it took the lead to develop the Framework for Indicators of the Combat against Wildlife and Forest Crime, Wildlife and Forest Crime Analytic Toolkit and Report on World Wildlife Crime, providing technical support for front-line law enforcement personnel to handle the wildlife crime linked to the Internet. On the other hand, it actively assisted the member states to effectively prevent and combat cyber crimes and initiated a "cybercrime information bank" under the framework of the U.N. Commission on Crime Prevention and Criminal Justice (CCPCJ), with cross-discipline research being conducted. In 2015, the General Assembly of the United Nations passed the resolution on "Tackling Illicit Trafficking in Wildlife" ${ }^{\prime \prime}$, recognizing the broader impact of wildlife crime, including corruption, money laundering, undermining good governance, the rule of law and the well-being of local communities, and calling on States to take appropriate action. INTERPOL played an important role in the fight against transnation- 
al organized crime and especially in coordinating its 192 member states to share information and establish a joint law enforcement mechanism. In 2014, INTERPOL Global Complex for Innovation (IGCI) was established in Singapore, dedicated to uniting law enforcement experts in cybercrimes and main partners in private sectors to assist the CITES contracting parties to fight the wildlife crime linked to the Internet. In June 2018, INTERPOL and IFAW jointly sponsored the Workshop on Cyber Wildlife Crime in France and at the meeting, it was pledged to tighten the collaboration between public and private sectors to stage a network for crackdown on online wildlife traffickers. In 2016, the CITES CoP17 passed the resolution No. 17.92 on Combating Wildlife Cyber Crime ${ }^{5}$ and requested the contracting parties to report to the secretariat their measures taken against cyber wildlife crime, improvement progress in laws and regulations and best practice on regulating online marketing and social media platforms. The 69th meeting of the CITES Standing Committee resolved to set up a working group on combating cyber wildlife crime to organize the experts in various areas to fight the crime. In 2018, at the London Conference on the Illegal Wildlife Trade, multiple signatories joined the Global Action Plan on Wildlife Cyber Crime $^{6}$. The EU has made positive contributions on Combating wildlife crime networks; it is well worth learning and reference. In 2016, the EU adopted the “Action Plan Against Wildlife Trafficking”. In 2019, EU passed new funding programs to destroy wildlife trafficking crimes within or via EU through Internet, postal service or courier service. We are very pleased to see these changes; it has increased our confidence in the fight against wildlife crime linked to the Internet.

In recent years, the international community also actively launched joint law enforcement actions and has conducted transnational investigations and successfully prosecuted multiple wildlife crimes linked to the Internet. For instance, in the "Operation COBRA III" initiated in 2015, Britain seized over 300 varieties of wildlife and their products, the majority of which were sold on the Internet.

\section{Experience and Challenges of China in Governing Wildlife Crime Linked to the Internet}

The Protection of wildlife is an important part of building the ecological civilization and building a beautiful China and it has a bearing on both ecological safety and national image (Jiao, 2015). China is a vast country, rich in wild species, vast in territory and diverse in customs. Many domestic and foreign criminals, taking advantage of loopholes and insufficient supervision, commit wildlife crime and distribute and transport them through the Internet. Since the 18th National Congress of the CPC, Chinese government pays great attention to building of

${ }^{5}$ See Combating Wildlife Cyber Crime, https://cites.org/sites/default/files/eng/cop/17/WorkingDocs/E-CoP17-29.pdf.

${ }^{6}$ See Global Wildlife Cybercrime Action Plan,

https://d1jyxxz9imt9yb.cloudfront.net/resource/31/attachment/regular/Global_Wildlife_Cybercrime _Action_Plan.pdf. 
the ecological civilization and takes wildlife protection and crackdown on illicit wildlife trade as an integral part of improving the ecological civilization. By following the principle of "protection first", it takes multiple measures and mobilizes various forces across the society to protect endangered wildlife. In terms of legislation, law enforcement and social comprehensive governance, China has always been standing at the forefront of combating illicit wildlife trade linked to the Internet.

\subsection{At the Level of Legislation}

At the level of legislation, in order to cope with the threat imposed by cybercrimes, China promulgated a series of laws and regulations to prevent and combat wildlife crime linked to the Internet. The newly revised Wild Animal Conservation Law came into effect on January 1, 2017. Its Article 31 and Article 32 stipulated that it is prohibited to run advertisement for illegally selling, buying and using wildlife products and it is prohibited to provide trading service for illegally selling, buying and using wildlife, wildlife products or the prohibited hunting gear by online trading platforms, commodity trading markets and other trading venues. It laid the legal foundation for combating the illicit wildlife trade on Internet and it was the first time that wildlife crime linked to the Internet was highlighted by legislation in China. In the Amendment (IX) to the Criminal Law of the People's Republic of China that took effect on November 1, 2015, one article is added after Article 287 as Article 287a: "whoever uses the information network to sell the contraband or release related illegal and criminal information, if the circumstances are serious, shall be sentenced to fixed-term imprisonment of not more than three years or criminal detention and shall, in addition, or shall only, be fined", and one article is added as Article 287b: "whoever provides technical support such as Internet access, server hosting, network storage and communication or offers help in advertising and promotion and payment and settlement for criminal acts, knowing that others use the information network to commit crimes, if the circumstances are serious, shall be sentenced to fixed-term imprisonment of not more than three years or criminal detention and shall, in addition, or shall only, be fined". This laid the foundation of regulation by criminal law for the crackdown on wildlife crime linked to the Internet.

Meanwhile, multiple laws and regulations further standardize the courier industry against illicit trade. In 2016, the Notice of the General Office of the State Council on Phasing out in Order the Processing and Sales of Ivory and Ivory Products for Commercial Purposes further clarified to "prohibit trading of ivory and ivory products via network and other channels" (Chen, 2017). The Postal Law, the Counterterrorism Law and the Regulations on the Control of Articles Prohibited from Delivery explicitly provided for use of the "real-name system", "registration system" and "mail inspection system for courier service" and requested inspections against contraband at both the receiving end and the consigning end. If a crime is constituted, criminal liabilities shall be investigated under the law. 


\subsection{At the Level of Law Enforcement}

At the level of law enforcement, Chinese government highlights the deepened cooperation among law enforcement departments and adopts a series of measures to fight wildlife crime linked to the Internet. In order to refine the long-term mechanism for inter-department coordinated enforcement, the State Council approved the establishment of the "inter-ministry joint meeting mechanism for combating illicit wildlife trade" in 2016 (Kou, 2017). The mechanism was led by the National Forestry and Grassland Administration and consisted of 25 ministries and departments such as the Ministry of Industry and Information Technology, Ministry of Public Security, Ministry of Ecology and Environment, Ministry of Transport, General Administration of Customs and State Post Bureau. In order to enhance building of the CITES performance ability, the Inter-National Department CITES Performance and Enforcement Coordinating Group and the Inter-Provincial Department CITES Performance and Enforcement Coordinating Group in China were set up one after another. In the meantime, Forest Public Security Bureau, National Forestry and Grassland Administration and Anti-Smuggling Bureau, General Administration of Customs launched multiple law enforcement campaigns. For instance, Spring Thunder 2018, a joint law enforcement campaign against wildlife crime initiated in 2018, was targeted at illicit wildlife trade on Internet platforms.

\subsection{At the Level of Comprehensive Governance}

At the level of comprehensive governance, Internet companies and courier companies enhance industrial collaboration and internal regulation to promote the conservation of wildlife.

On the one hand, Internet companies actively took measures to handle the illicit wildlife trade, from tackling the trade on their own platforms with a "zero tolerance" attitude to setting up the consortium to combat wildlife crime linked to the Internet. In 2017, China's top three Internet companies (Baidu, Alibaba, Tencent) joint hands with another eight Internet players to initiate the Coalition to End Wildlife Trafficking Online (Xinhua Net, 2017). In 2018, the Coalition and 10 technology magnates such as Google, Facebook and eBay further formed the Global Coalition to End Illegal Trade in Wildlife Online and jointly pledged to reduce the illicit wildlife trade online by $80 \%$ by $2020 .^{7}$ So far, the Coalition has up to 32 members. In 2018, the Coalition members utilized such technologies as image recognition, machine learning and artificial intelligence to delete roughly one million pieces of online information on illegal wildlife trade, block more than 10 million pieces of illegal ads and delete 350,000 illegal accounts in China.

On the other hand, efforts were made to improve ability building in the courier and transport industry and enhance industrial collaboration to contain the illicit wildlife trade. In fact, more than half of the seized illegal wildlife prod-

${ }^{7}$ More details refer to: https://www.endwildlifetraffickingonline.org. 
ucts were seized at the stage of transport. In 2015, 17 leading courier companies hosted a training workshop on the transportation of protected wildlife and wildlife products and signed the "zero tolerance" commitment. In 2016, the United for Wildlife Transport Taskforce initiated the Buckingham Palace Declaration against illicit wildlife trade and currently, Chinese enterprises such as China Southern Airlines and China Post have signed the Declaration. In 2019, Chinese courier industry sponsored the signing ceremony for the "Self-discipline Convention on the Rejection of Delivery of Illegal Wildlife and Wildlife Products". 12 Chinese courier companies such as EMS, SF-Express and YTO-Express and two international courier magnates namely DHL and FedEx signed the Convention and made the commitment to take various effective measures to curb the illicit wildlife trade (Guo, 2019).

\subsection{Main Challenges}

Though China has made tremendous efforts and achieved noticeable progress in combating the wildlife crime linked to the Internet, it is far from enough given the fact that illicit trade on Internet is gigantic in size and boundary-free. Besides the many legal issues and the law enforcement challenges related to traditional wildlife crime, Internet-based illicit wildlife trade still faces many other problems that need be tackled urgently.

Main challenges are as follows. Firstly, wildlife crime linked to the Internet is highly elusive, making online regulation and investigation increasingly difficult. As Internet is open, uncertain, virtual and beyond time and space, crime linked to the Internet is highly elusive (Liu, 2007). Therefore, it is increasingly hard to conduct criminal investigations and collect electronic evidence and it is also difficult to identify species, source and trade volume of wildlife crimes and even more difficult to prosecute. For example, criminals rarely use descriptive terms related to illegal wildlife products when running advertisement or negotiating trading details online, but usually use alternative names to describe the products. In this way, they can effectively avoid being identified or detected and get access to excuses for counterargument. Secondly, criminal jurisdiction over crime linked to the Internet faces new challenges. There are always conflicts between the crime linked to the Internet that is boundary-free and elusive and jurisdiction that is intrinsic to the legal system, and the former poses tremendous challenges on the existing criminal justice procedures and jurisdiction of the countries. In pure wildlife criminal cases in China, jurisdiction obviously follows the "principle of territory". However, in transnational wildlife crime linked to the Internet, jurisdiction becomes more and more complex and it is difficult to identify where a crime occurs, place of origin of wildlife, place of residence of criminals, registered place of Internet address or place subject to influence of the crime. Thirdly, with respect to the "linkage between administrative enforcement and criminal justice" against wildlife crime linked to the Internet, "no movement on cases and replacement of criminal penalties with fines" has become serious 
problems in administrative enforcement. Currently, administrative laws and regulations have specific provisions on illicit wildlife trade online, but the criminal law has not been revised correspondingly. Consequently, serious wildlife crime linked to the Internet cannot be regulated by criminal law, inevitably resulting in the "replacement of criminal penalties with fines".

\section{Advice for Improving the Governance against Wildlife Crime Linked to the Internet in China}

As new business types and new business modes such as e-commerce and social platforms keep emerging, eradicating wildlife crime linked to the Internet remains a long-lasting and arduous task. It is necessary to construct an all-round and multi-layered efficient governance mechanism against the wildlife crime linked to the Internet with multiple parties collaborating.

\subsection{Refining Legal Regulation against the Crime}

Firstly, with regard to substantive law, laws and regulations such as the Criminal Law, the Wild Animal Conservation Law and the Regulations on Wild Plant Protection should include online advertising, a key step in wildlife crime linked to the Internet, into criminal law regulation, identify legal regulation issues on artificially reproduced wildlife and improve related rules on legitimate wildlife trade online. Secondly, with respect to procedural law, it is important to refine the special investigation procedures of crime linked to the Internet, address the issue on particularity of electronic forensics and ensure that law enforcement organs enjoy sufficient power for investigation and prosecution. Meanwhile, it is necessary to explore the burden of proof for wildlife crime linked to the Internet. For example, sellers can be requested to shoulder the legal burden of proof for providing necessary supporting documents. Thirdly, the "linkage between administrative enforcement and criminal justice" for tackling the wildlife crime linked to the Internet should be enhanced. Currently, the Wild Animal Conservation Law provides that it is prohibited to provide trading service for illegally selling, buying and using wildlife, wildlife products or the prohibited hunting gear and that if a crime is constituted, criminal liabilities shall be investigated under the law. However, the Criminal Law does not include specific provisions on the type of crime and it should be taken into consideration in the new amendment to the Criminal Law.

\subsection{Strengthening the Law Enforcement Mechanism against the Crime}

Firstly, according to related CITES resolutions, law enforcement organs targeting wildlife crime linked to the Internet can be set up on the national level to strengthen coordination and joint regulation, with the boundary among jurisdiction of different departments being eliminated. Meanwhile, attempts can be made to establish wildlife online trade monitoring mechanisms on the national 
level. With the help of current technology, as guided by big data and big intelligence, a national collaboration platform for wildlife case investigation and control can be gradually put into place and the information database on wildlife cases can be developed, with such functions as internal information collection, automatic comparison and intelligence early-warning to be refined (Wu \& Lian, 2017). Secondly, the advantages of the inter-ministry joint meeting mechanism and the national- and provincial-level Inter-department CITES Enforcement Coordinating Group should be put into full play to ensure establishment of an efficient mechanism on joint clue search, intelligence sharing and joint combat. Thirdly, the cooperation and coordination mechanism between law enforcement departments and the private sector need be enhanced. Practice proves that the Chinese cooperation mode between law enforcement departments and the private sector is an effective instrument for combating illicit wildlife trade and it is necessary for government to take the lead and for law enforcement departments and Internet companies, the courier industry and financial institutions to set up a long-term cooperation mechanism. Fourthly, the linkage mechanism between administrative enforcement and criminal justice targeting the illicit wildlife trade online need be further bettered. It is important to put into place systems on information sharing, circulation of case details and case referral by administrative enforcement institutions, public security organs, procuratorial organs and judicial organs. "No movement on cases, difficulty in making movement on cases and replacement of criminal penalties with fines" shall be firmly overcome to realize the seamless connection between administrative punishment and criminal penalties. Fifthly, legal publicity should be stepped up to enhance the legal awareness of the public. Law enforcement organs should conduct legal publicity and promotion on wildlife education and such laws as the Criminal Law, the Wild Animal Conservation Law, the Cyber Security Law and the Advertisement Law, so as to improve the public awareness of conservation, purify the network environment and shape a governance picture of "participation by multiple parties, prevention and control by the masses".

\subsection{Perfecting the Comprehensive Governance Mechanism against the Crime}

The private sector plays a significantly important role in the combat against the illicit wildlife trade online and should be encouraged and also enhanced continuously. In many cases, the private sector has been able to get closer to the front line and get a better sense of what's going on. They know the best way to solve the problem.

On the one hand, it is necessary to strengthen the ability building and industrial collaboration of Internet companies and the courier industry. Related industries should keep refining their own ability building and better the abilities in monitoring, identifying, disposing and preventing the illicit wildlife trade. Meanwhile, more and more Internet companies should be encouraged to join the Coalition to End Wildlife Trafficking Online and the Global Coalition to 
End Illegal Trade in Wildlife Online and increasingly more transport enterprises should be encouraged to join the Buckingham Palace Declaration, so as to perfect the industrial collaboration mechanism and form greater synergy.

On the other hand, engagement of non-governmental organizations and the public need be reinforced. Non-governmental organizations such as TRAFFIC China should continue to monitor the online wildlife trade and meanwhile assist law enforcement institutions to effectively regulate online trade. Non-governmental organizations such as China Wildlife Conservation Association and China Wild Plant Conservation Association should further intensify their publicity efforts on wildlife conservation and legal education and strive to improve the public legal awareness of wildlife conservation, so that the concept of "no business, no harm" can be deeply rooted in people's mind, without a buyer's market, criminals can't make money, At the same time, we should also continue to increase publicity, starting from children, cultivate children's awareness of nature protection, consumers' behaviors can be truly changed, consumer demand can be reduced and crimes can be prevented fundamentally.

\subsection{Enhancing the International Cooperation Mechanism against the Crime}

1) At the domestic level

On the one hand, China should actively perform related international conventions and fulfill related political commitments. It should proactively carry out related resolutions such as Tackling Illicit Trafficking in Wildlife and Combating Wildlife Cyber Crime and join the Budapest Convention, the only international legal instrument that targets cybercrimes, at proper times. On the other hand, efforts need be made to improve the global cybercrime information sharing mechanism, stage bilateral and multi-lateral enforcement cooperation mechanisms for combating the wildlife crime linked to the Internet, relying on the Chinese government alone cannot fundamentally solve the problem, actively participate in international joint enforcement actions and work with the international community to fight crimes together.

2) At the international level

Of course, on the international level, tackling the wildlife crime linked to the Internet requires the joint efforts of government of all countries and related international organizations. On the one hand, it is urgently needed to refine the legal regulation on the crime by international legislation. The Budapest Convention needs to be further improved and include the serious wildlife crime linked to the Internet. It is necessary for the CITES to put into effect a new policy to define online advertising and selling of species in its Appendix I as crime. Feasibility and necessity of the policy have already been confirmed by the CITES Taskforce on Wildlife Cybercrime. On the other hand, major international organizations should perfect their macro guidance over global efforts against wildlife crime linked to the Internet. The CITES secretariat should further conduct en- 
forcement and investigations, provide more technical assistance and expertise, and share domestic measures, best practice and guides on tackling the crime collected by various parties via information portal websites more often. TRAFFIC, as the world's largest wildlife trade monitoring organization, should establish long-term and effective monitoring mechanisms, expand the scope of monitoring, study the development trend of crimes and propose targeted advices on countermeasures. In the meantime, the Manual on Standard Operation Procedure for E-commerce and Logistics should be formulated as soon as possible (Xinhua Net, 2017), so as to guide Internet companies to identify, prevent and dispose of information on wildlife crime linked to the Internet. INTERPOL should develop and share the implementation guideline for controlling and combating the illicit wildlife trade as soon as possible, put forward measures for detecting, disposing of and preventing wildlife crime linked to the Internet and offer technical assistance. UNDOC should further put into effect and improve the international database on wildlife crimes. China, as a contracting party of related international conventions and a member state of major international organizations, should actively participate in and support the international cooperation mechanisms on combating the crime linked to the Internet.

\section{Conflicts of Interest}

The authors declare no conflicts of interest regarding the publication of this paper.

\section{References}

Chen, S. (2017). China Will Fully Suspend Processing and Selling of Ivory and Ivory Products by the End of This Year. China News Net. https://www.guancha.cn/society/2017_03_24_400348.shtml

Cites Report (2019). Interpretation and Implementation Matters General Compliance and Enforcement Combating Wildlife Cybercrime. https://cites.org/sites/default/files/eng/cop/18/doc/E-CoP18-033-02.pdf

Cnnic Report (2019). The 44th China Statistical Report on Internet Development Released by China Internet Network Information Center. http://www.cac.gov.cn/pdf/20190829/44.pdf

Guo, D. D. (2019). Chinese and Foreign Express Delivery Industry Jointly Combat Illegal Transportation of Wild Animals and Plants. China Green Times (May 13, 2019). http://www.greentimes.com/greentimepaper/html/2019-05/13/content_3332989.htm

Huanqiu Net (2019). Chinese Internet Magnates Initiate the Coalition to End Wildlife Trafficking Online. https://hope.huanqiu.com/article/9CaKrnK5OP9

IATA (2019). Illegal Trade in Wildlife Fact Sheet. https://www.iata.org/pressroom/facts_figures/fact_sheets/Documents/fact-sheet-wildlif e.pdf

IFAW (2018). Disrupt: Wildlife Cybercrime. https://d1jyxxz9imt9yb.cloudfront.net/resource/223/attachment/regular/disrupt-wildlif e-cybercrime.pdf

IFAW (2014). Wanted-Dead or Alive Exposing Online Wildlife Trade. 
http://www.indiaenvironmentportal.org.in/files/file/IFAW-Wanted-Dead-or-Alive-Ex posing-Online-Wildlife-Trade-2014.pdf

Jiao, Y. H. (2015). Combating Wildlife Crime Requires the Joint Efforts of the International Community. China Green Times (June 19, 2015). http://www.greentimes.com/greentimepaper/html/2015-06/19/content_3270683.htm

Kou, J. Z. (2017). Inter-Department Linkage Mechanism in Combat against Wildlife Trafficking Officially Put into Operation. People's Daily (Apr. 12, 2017). http://politics.people.com.cn/GB/n1/2017/0413/c1001-29206731.html

Liu, Z. (2007). Characteristics of e-Commerce Crime and Preventive Measures. Journal of Hunan Business College, 3, 96.

Qin, H. X. (2016). Necessity of Intelligence Work under the Context of Wildlife Protection Globalization. Chinese Journal of Wildlife, 3, 277-282.

SPB Report (2019). The 2017 Regulatory Report on the Courier Market. http://www.spb.gov.cn/zy/xxgg/201807/P020180731370190482670.pdf

Traffic Report (2019). Combating Wildlife Crime Linked to the Internet-Global Trends and China's Experiences.

https://www.traffic.org/publications/reports/combating-wildlife-crime-linked-to-the-in ternet

Wu, G., \& Lian, H. C. (2017). Study on Investigation and Prevention Measures against Online Wildlife and Product Trafficking Crime. Forest Public Security, 5, 34-37.

Xinhua Net (2017). Coalition to End Wildlife Trafficking Online Founded in Beijing. http://www.xinhuanet.com//gongyi/2017-11/23/c_129747799.htm

Xinhua Net (2019). World Animal Protection Releases the First Report on Global Wildlife Exotic Pet Trade.

http://www.xinhuanet.com//gongyi/2019-02/21/c_1210000704.htm

Xu, C. Q. (2017). Study on Governing Modes against Cybercrime. Doctoral Thesis, Dalian: Dalian Maritime University. 